\title{
THE APPLICATION OF HOLISTIC RISK MANAGEMENT IN THE BANKING INDUSTRY
}

\author{
J Chibayambuya \& DJ Theron, University of Johannesburg
}

Purpose: The application of holistic risk management is fast becoming a standard measure of good governance in the business arena. What role can holistic risk management play in the management of risk in the financial services industry? The aim of this paper is to propose a holistic risk management framework for the management of risk.

Design/Methodology/Approach: A comprehensive framework that covers the holistic view risk management is proposed/developed out of an extensive literature review.

Findings: Given the deliberations of various frameworks, a holistic risk management is proposed. The proposed framework ensures that all components of risk management are taken into account when strategizing for risk management in general and holistic risk management in particular; thereby improving the management of risk in the banking industry.

Implications: The article proposes a holistic approach to risk management which takes into account all the facets of risk management, e.g. analyzing, planning, strategy, communication, implementation, motivation, systems review and plan modification. This holistic approach, when implemented in the banking industry, can have a significant impact on the improved management of risk.

Originality/Value: The new proposed holistic risk management framework offers a fresh perspective of strategizing for risk management in terms of risk analysis, risk planning, risk strategy, risk communication, risk implementation, risk motivation, risk review and risk plan modification.

Key words and phrases: Operational risk; Strategic risk; Holistic risk management; Top-Down approach: Bottom-up approach.

\section{INTRODUCTION}

The existence and viability of banks relies heavily on the management of risks with the responsibility on the board of directors and management to identify, measure, monitor, control and verify different risks within the banking industry. This article highlights that conventional risk management theory may no longer be appropriate within the changing banking environment of today and this translates into a need to nurture a culture within banks that values a proactive and holistic manner in managing risks. In this respect, holistic risk management (HRM) is a response to the growing need for a benchmark of the best practice for those who manage and regulate complex banking activities. It sets out a comprehensive framework, comprising eight-nine core principles, with which such banks can manage their risk and through which regulators can benchmark the adequacy of management practices operated at individual banks or organizations.

The article begins with an exploration of what risk management is. Risk management as a core activity in banking and the approaches to and processes applied to risk management in the banking industry are then explored. Due to the important role of effectively managing risk in this dynamic industry, holistic risk management is then proposed as a method of optimally achieving the effective management of risk. Here the various author's work on the concept of holistic risk management is explored, followed by the development of a holistic risk management framework. This framework comprises of the following eight steps, namely: (1) holistic risk analysis; (2) holistic risk planning; (3) holistic risk strategy; (4) holistic risk review and communication; (5) holistic risk implementation planning; (6) holistic risk motivation and control; (7) holistic risk systems review of results; and (8) evaluation and plan modification. 


\section{RISK MANAGEMENT APPROACHES IN THE BANKING INDUSTRY}

Risk management pertains to situations for which previous probability data exists that are useful in predicting future outcomes, whereas uncertainty pertains to situations where there is no suitable past data on which to estimate the chance of an occurrence. A risk situation is therefore a situation in which a probability distribution for outcomes is made on a meaningful basis and is therefore known. Uncertainty exists therefore when there is an unknown, undefined probability distribution on a set of outcomes. Risk is furthermore insurable, whereas, uncertainty can only be described by intuition. Risk management can be identified as being objectively conceived, and uncertainty as a relationship between subjective probability distributions. There is a grey area of 'uncertain risk', which belongs to both risk and uncertainty. In view of this argument and the notion that risk and uncertainty are both areas where substantial and severely detrimental losses can be incurred, this paper will view risk and uncertainty as inextricably linked. The two concepts will therefore be used interchangeably (Bank of England, 2000:117; Shimpi, 2002:128; Van Dam, 2001:141; Vaughan \& Vaughan, 2004:487-520; Barton, 2002:19; Shimpi, 2002:128; and Lam, 2003:284).

The business of banking activity involves a key component of risk management which is defined as the responsibility of management to identify, measure, monitor, communicate and control risk within an institution. The process therefore consists of risk identification, risk assessment, evaluation of risk alternatives, selection of an alternative or risk control measure, communicate and the ongoing monitoring of the risk management program (Price, 2000:299-330). In order to accomplish these objectives, two interrelated management approaches, namely strategic management linked to a top-down and bottom-up management approach are applicable.

\section{The Strategic Management Approach}

The banking industry finds itself in a highly competitive marketplace and has to produce successful organisational performance through crafting and implementing pro-active business strategies. In this respect, Roux (1996:72-123) documents the strategic management process with the objective of establishing a means for banks to determine and execute their business strategies. Roux (1996:124) furthermore alludes to the corporate strategy formulation process including the importance of a mission-vision directional picture; environmental analysis; critical success factors; goals and objectives; and values and ethics. The importance of implementation of strategies; business plan formulation; and strategic control and strategic adjustments are also described. The same author provides a brief glimpse of strategic management in four South African banks and emphasises the importance of incorporating risk management into strategic management process. This is necessary as banks manage more complex and volatile market risks and thereby attract greater regulatory scrutiny. Kreps (1994:53) subscribes to this notion by suggesting that banks make use of sophisticated models for allocating capital on a risk-adjusted basis. In this regard Roux (1996:129 -187) suggests a conceptual risk-based strategic business model for assessing levels of risk and to focus on certain risk activities within a bank.

The problem of risk management in banks, however, goes beyond the conventional strategic management paradigm and risk based models. It manifests itself as a need for managing risk in a pro-active manner. The Banks Act of 1990 (1990), in conjunction with the regulations promulgated under it, places considerably more emphasis on risk management as the basis for supervision of banks than was previously the case (Van Zyl, Botha \& Skerritt, 2006:85). Two perspectives to the management of risk prevail, namely a 'top down' and 'bottom-up' approach as illustrated in Figure 1. 
Figure 1: Top-down and bottom-up approach

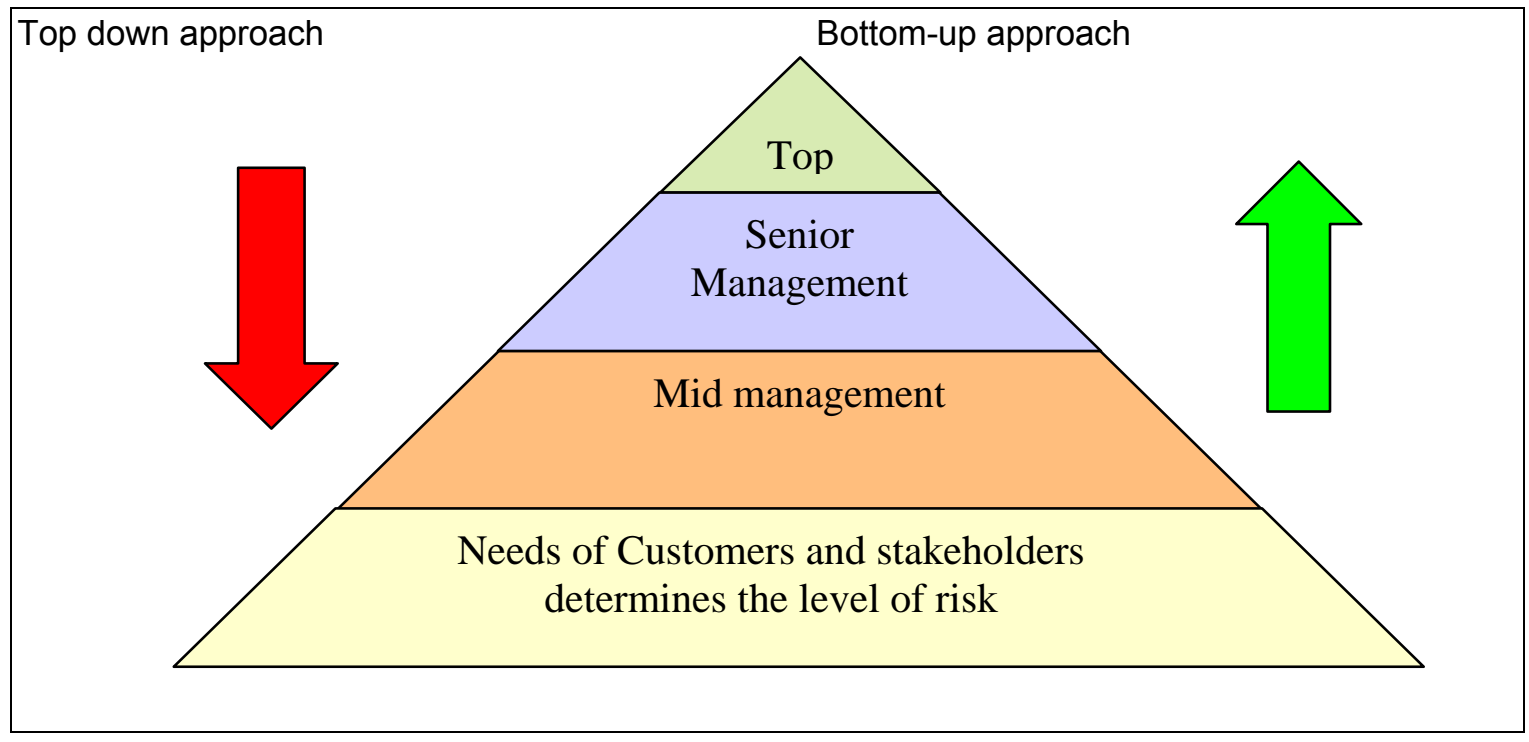

Source: Adapted from Baliman (1999:19) and Chibayambuya (2005:55)

- Top-down approach

The 'top-down' approach to risk management, according to Baliman (1999:106), indicates that top management imposes its weight in terms of risk strategies, controls, rules, policies and regulations. Middle management is expected to deliver according to the prescribed strategies, controls, rules, policies and regulations by top management.

- Bottom-up approach

According to Chibayambuya (2005:162) the 'bottom-up' approach is driven by the needs of traders and customers on the short-term concerns of the bank. For example, questions of making a profit from principal exposures while controlling risk amid constantly changing markets. The latter perspective has predominantly driven advances in risk management technology. Against the background of an expansion in the derivatives market, the ability to price instruments competitively and to manage the risk therein safely, has depended critically on tactical measures of risk (Regester \& Larkin, 2005:173). At the same time, the need to manage banks as a whole has been reinforced by several high profile cases and encouraged by central banks and regulatory authorities. Given the availability of tactical risk measures, the general tendency has been to build up these bottom-up measures in order to produce total measures, which are then taken to represent the strategic risk in a bank. Regester and Larkin (2005:135) argue that this process on its own produces narrow and non-comprehensive measures of strategic risk. The authors furthermore point out that the communication part of risk management is totally ignored by top management.

Regardless of the approach implemented, banks have developed a number of processes for the purpose of managing risk.

\section{RISK MANAGEMENT PROCESSES IN THE BANKING INDUSTRY}

GARP (2003:36) proposes that the risk management process should incorporate the following elements: The elements of the Risk Management Process and their Principles include: 
- Risk Assessment: Identify and value the organisation's total assets and resources. Identify major exposures to loss. Evaluate and communicate current and potential risk.

- Risk Control: Support proactive risk and loss-control program. Provide maximum incentive for participation in risk control program. Monitor effectiveness of risk control activities.

- Risk Financing: Finance risk, considering all available financial resources. Maintain appropriate catastrophe protection. Allocate risk financing costs among operating units on an equitable, understood, and acceptable basis.

- Administration: Create and sustain management commitment to risk management. Adopt a clearly defined risk management structure. Develop clearly targeted annual objectives. Maintain sound communications with all affected levels of management.

These principles can serve as the framework of a full review of the risk management process within any financial institution. They can be a benchmark for strategies and tools employed by other successful managers. They are certainly not the final answer but, as they are based on over ten years of practical experience, they can be an important building block for a successful risk management program (Pinchot, 2000:14).

Chibayambuya (2005:291) proposes that the following risk assessment process should be followed:

- Input - consisting of brainstorming, management discussion/clarification and risk ranking.

- Output - consisting of identification of risks, merging/clarification of risks and rating of risks on their impact and likelihood.

- Process - consisting of listing and rating of various risks in order of their severity. The whole process in depicted in Figure 2.

Figure 2: The risk assessment process

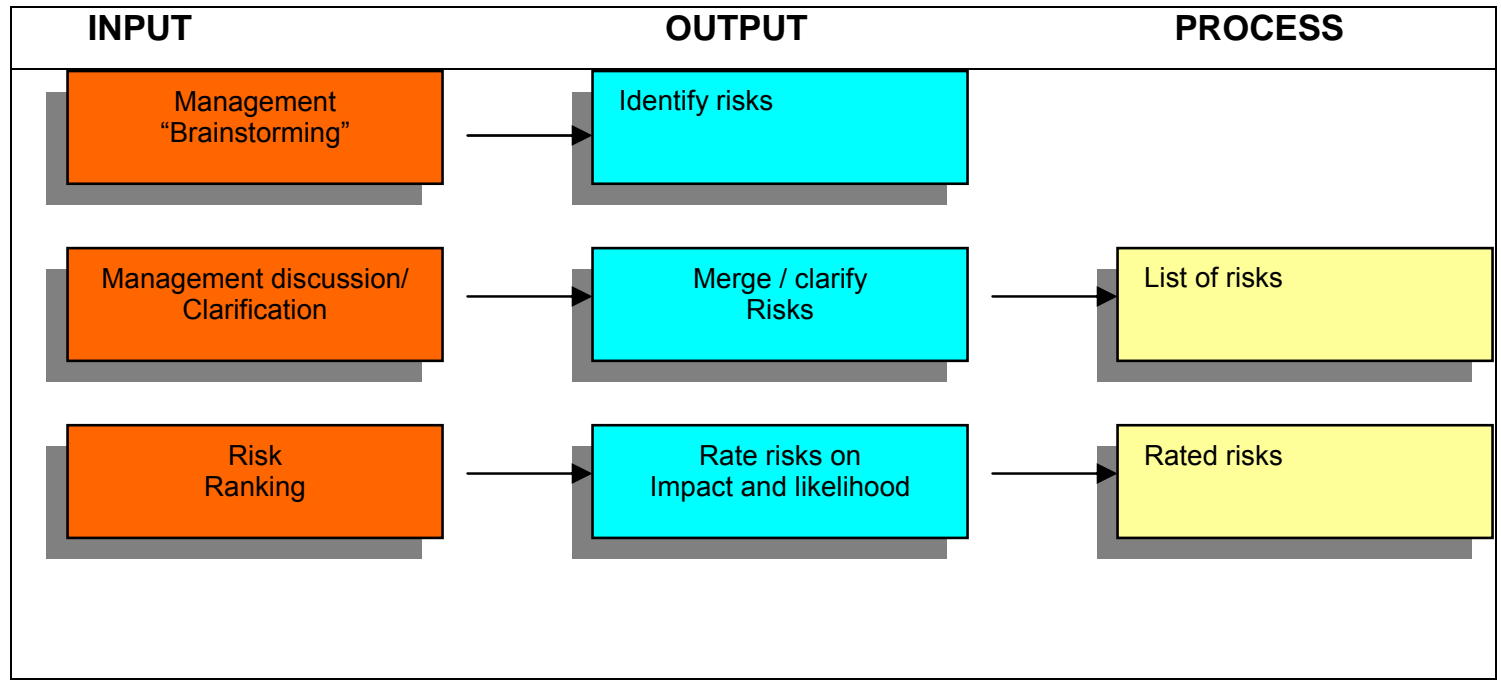

Source: Adapted from Chibayambuya (2005:291) 
Now that the risk management approaches and processes in the banking industry have been explored, holistic risk management is introduced and explored in more detail.

\section{HOLISTIC RISK MANAGEMENT IN THE BANKING INDUSTRY}

Holistic risk management is a concept about managing all the risks simultaneously. Holistic risk management is all about accountability - that is taking responsibility for their actions. People must be able to accept the results of their actions. Lack of accountability, or the perception of it, is a good way for shareholders to lose faith in an institution's management, clearly a bad thing for the institution (Payne, 2000:174).

Holistic risk management (HRM) involves a methodology where the various risk types that can affect a bank are considered holistically, rather than independently. Broadly speaking, there are two basic types of risk: strategic risk and operational risk. Various authors have investigated this concept and their findings are explored below.

\section{Holistic Risk Management According to Lam}

Lam (2003:58) believes that holistic risk management should be managed as depicted in the Jigsaw framework. In the middle, he proposes that the bank should have an enterprise risk management framework (ERM). The ERM should in turn manage the various risk legs for example operational risk, credit risk, market risk, business risk and other related risks. This is illustrated in Figure 3.

Figure 3: The jigsaw holistic risk management framework

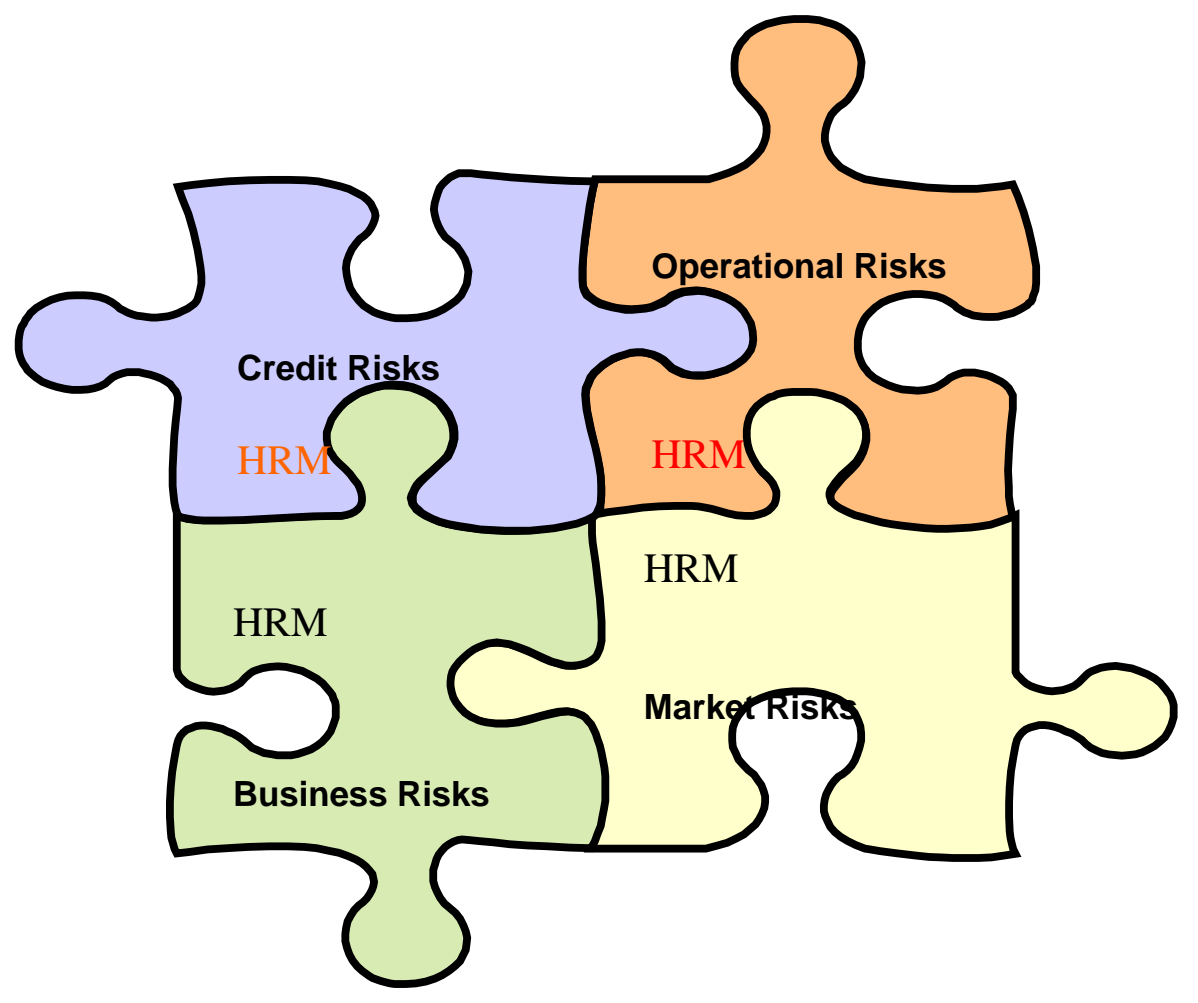

Source: Adapted from Lam (2003:76) 
These risks are somewhat analogous to the classical elements of earth, air, fire and water. Just as "earth" includes everything from rock to steel, so this definition of credit risk includes everything - from a supply chain failure to a debt going bad. And just as the classical elements can be combined to make up new substances - earth and water to make mud, for example - so these elemental risks can lead to form new ones. For example, the apparently minor operational risk of a slight time disjunction between settlement systems, or a temporary failure in one of the systems, can combine with credit risk exposure to create massive settlement risks. However, Lam (2003:216) does not talk about strategic and operational risks in isolation. His Jigsaw frameworks talks about the holistic risk management (HRM) in the middle and surrounded by strategic, operational, business, market, credit and a whole range of other risks. He rightly states and gives provision for other types of risks to be added to his Jigsaw framework, but not strategic and operational in this order.

\section{Holistic Risk Management Strategies According to Lam}

Lam (2003:204) proposes the seven step strategy for holistic risk management as follows:

\section{- Strategy 1: Know your business}

It is common knowledge that managers are obligated to know their businesses. However, it should be mandatory that everybody in the organisation share this obligation. According to Lam (2003:117), it is important that all employees understand how their individual accountabilities could affect the risks of the organisation and how their functions and responsibilities relate to others within the company. This increases risk awareness at an enterprise wide level, which is highly encouraged in holistic risk management.

\section{- Strategy 2: Establish checks and balances}

It is of vital importance, in any financial institution, that power and authority is devolved so that there is not one individual or a group of individuals who wield excessive power. Lam (2003:18-19) cites the collapse of Barings Bank as a classical example where a lack of adequate checks and balances led to the "rogue trader" Nick Leeson, to conceal mounting losses for over a year with negative consequences to the bank when the losses did eventually erupt. By nature, people like power but too much of it without built-in checks and balances is bound to cause corruption.

- Strategy 3: Set limits and boundaries

"Just as business strategies and product plans tell a business where to go, risk limits and boundaries tell a business where and when to stop" (Lam, 2003:129). With a carefully orchestrated and executed holistic risk management policy, together with clearly defined checks and balances, it becomes easy for organisations to know their limits and boundaries that will help in a big way to minimise exposures.

\section{- Strategy 4: Keep your eye on the cash}

Cash is the single-most important asset to any organisation hence the contention by Lam (2003: 20 ) that it is important to make sure that adequate measures are designed and implemented for the proper management of cash positions and cash flow. Improper cash flow management led to the collapse of industrial giants such as Enron and Kidder Peabody to mention just but two. Cash is the life blood of any organisation. Without cash, no organisation can function.

- Strategy 5: Use the right yardsticks

Measures used by different organisations to track and manage individual performance levels are a key driver to human behaviour. To this end, Lam (2003:20-21) advocates for the use of a 
"balanced scorecard" in the establishment of performance measures that are geared toward quality, customer satisfaction and internal processes as a management tool to improve the bottom line and proactive risk management.

- Strategy 6: Pay for the performance you want

Compensation is a sticky issue in management but it is imperative to management that this issue is critically evaluated nonetheless. It is important to establish whether compensation and incentives are producing the desired levels of performance and rewards to the organisation. According to Lam (2003:21), compensation and incentives are probably the key drivers of human behaviour and as such, it has a significant potential to impact, negatively or positively, on the organisation in general and risk management in particular.

\section{- Strategy 7: Balance the yin and the yang}

It is of absolute importance to any given organisation to strike a balance between the "hard" and "soft" aspects of risk in order to have a holistic appreciation of all different risks to which an organisation is exposed. According to Lam (2003:22), the hard side comprises of processes, systems and reporting while the soft side focuses on the people, skills, cultures, values, training and incentives. Balancing the "hard" and the "soft" aspects of risk management is critical to the application of holistic risk management.

Another leading author's views (those of Kloman) on holistic risk management are explored below.

\section{Holistic Risk Management According to Kloman}

Kloman (2003:171) proposes that holistic risk management should be managed as depicted in Figure 4. Kloman (2003:172) maintains that all the risks emanate from global risks. He believes that the global risks ranging from political fragmentation, pandemics, nuclear proliferation, religious fundamentalism, population explosion, and climate change are the drivers of the organisational risks the banking industry faces today.

\section{Figure 4: Holistic risk spectrum framework}

\section{The Risk Spectrum}

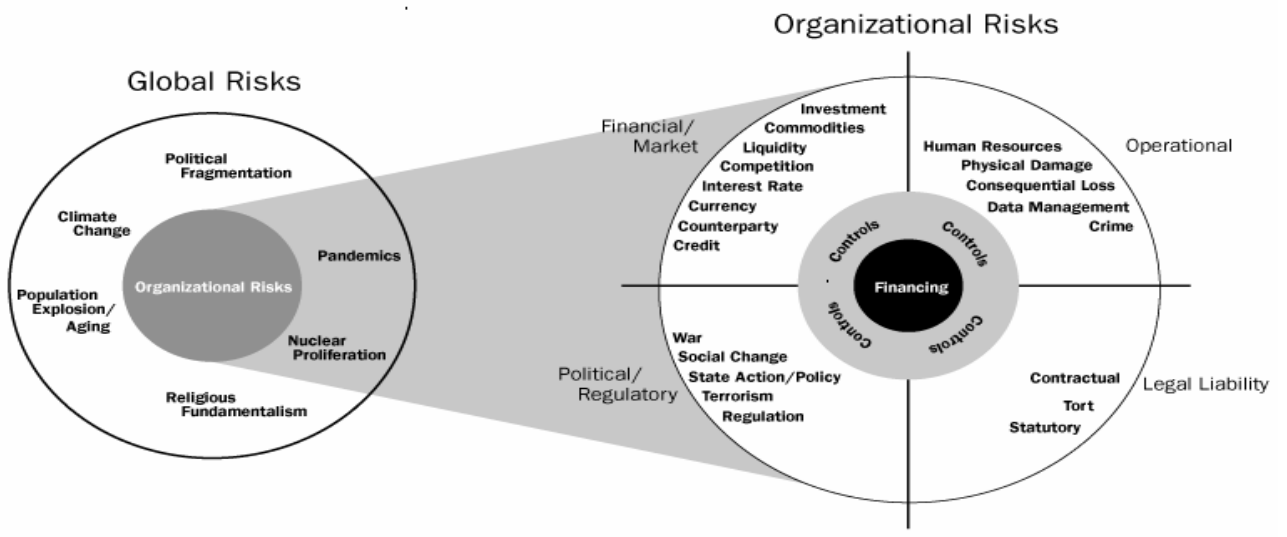

Source: Adapted from Kloman (2003:173) 
Financial/market risks, according to Kloman (2003:172), includes credit, counterpart, investment, competition, liquidity, interest rate, market, and currency, while insurance risks include all that has to be covered. Quality assurance includes operations, capital adequacy, and legal. Securities includes bonds, guarantees, collateral safety and includes the safety of both clients and staff. Public policy includes all policies, strategies, missions and visions of the bank.

Holistic risk management operations according to Kloman (2003:175) includes human resources, physical damage, consequential loss, data management, and crime. Legal risks, political/regulatory risks, financial risks, political risks, and operational risks form the outer layer of his spectrum of risk. The inner layer according to Kloman (2003:172) is the control element and then the centre is the bank / the organisation.

All the organisational risks are specific and are driven by other forces for the purpose of this article, known as global risks. Global risks for the purpose of this article are climate change, political fragmentation, pandemics, nuclear proliferation, religious fundamentalism and population explosion/aging.

Given this differing way of looking at and classifying risk, Kloman has developed the "ten commandments" of holistic risk management, explored in more detail below.

\section{The Ten Commandments of Holistic Risk Management According to Kloman}

The ten commandments of holistic risk management fall into categories or themes, which according to Kloman (2003:214-230), include:

- Honor thy yacht: Proper respect for your organisation, its products and services, its people, its suppliers and customers, and its communities - in a word, its stakeholders, is essential for sound holistic risk management.

- Thou shalt not tempt Mother Nature: A thoughtful risk manager recognises the external forces at work on the organisation and is not too rash.

- Be neat in thy work: Sloppy work takes less time but the results are all too evident. Take time to create and maintain clear and coherent records. Don't rush your work because of the unrealistic deadlines of others.

- Understand thy chosen finish: Study carefully all possible responses to risk, ranging from avoidance and mitigation to various forms of financing. Assure yourself of the best "finish" or combination of "finishes."

- Do thy product research: Know the pros and cons of services and service providers, such as risk assessments, actuarial analyses, technical controls, claims services, and insurance contracts, enabling you to use them confidently and know what to expect from each one.

- Know thy hardwoods: Make sure that you know your own organisation as well or better than anyone else. Understand its people, its products, services, and facilities. Don't compromise by accepting the opinions and views of others: go forth and see for yourself - often.

- Neglect not thy detailing: When reports, analyses, papers, and contracts pertaining to risk management are prepared, make sure that you read and understand them. Don't depend on the analyses of others. Study risk assessments and read insurance contracts, tedious as this may be.

- Keep thee safe and alive: Self-preservation is important, in terms of both physical safety and health and the function of risk management within the organisation. Practice the risk controls you preach. Stress the importance of risk and loss control. 
- Keep the preventive maintenance creed: Pre-emptive action is the ounce that easily outweighs the pound of cure required later. Early action generally prevents paying more for later losses.

- Thou shalt love working on thy yacht: Some years ago, Tom Peters noted that many leaders of highly successful companies shared a distinguishing characteristic: their "love of product." If you don't enjoy risk management work, seek another line. Your lack of passion will show up quickly.

Above all, be patient. Changes take time because large organisations are hard to move. Entrenched bureaucracies, common to government, corporations, and services, protect their own systems, but persistent pressure will, over time, produce favourable results.

\section{The Role of Holistic Risk Management According to Regester and Larkin}

A number of authors such as Kloman (2003:193), Shimpi (2002:93), Lam (2003:167) and Regester and Larkin (2005:279) are of the opinion that the board of directors is irrevocably responsible for the assurance of shareholder's value, it is therefore accountable for any financial loss or reduction in shareholders value that may arise due to poor application of holistic risk management controls. Furthermore, the board is expected to recognise all the risks to which the bank is exposed to and to ensure that the mandatory ethnicity, practices and systems are in place, as it cannot afford to expose the bank's risk tolerance when allocating capital to its business units.

Management responsibility is under normal circumstances delegated by the board to the executive committee. The executive committee, in turn, is supported by a holistic risk management group (or equivalent) whose primary role is to delineate the bank's holistic risk management policies and to ensure that appropriate procedures, controls and investment systems are in place. The holistic risk management group must also be impartial to dealing and related functions (Regester and Larkin, 2005:139).

Regester and Larkin (2005:374) concur with Lam (2003:272) that the holistic risk management function involves the day-to-day monitoring, measuring and evaluation of risk and should be managed by an appointed head of risk who is a member of the holistic risk management group. In addition, the holistic risk management function also implement the risk policies associated with market, credit and liquidity risks arising from trading activities. The holistic risk management function should possess adequate knowledge in financial products including derivatives and must operate independently from risk generating business units and trading area.

Now that the concept of holistic risk management has been explored, a holistic risk management framework is proposed.

\section{TOWARDS A HOLISTIC RISK MANAGEMENT FRAMEWORK}

A number of authors, namely: Bernstein (1998); Kloman (2000); Aldred (2001); Shimpi (2002); Lam (2003); Morrison (2004) and Regester and Larkin (2005) have established various frameworks to manage holistic risk management. They all concur that the ideal holistic risk management framework must include the following categories: (1) holistic risk analysis, (2) holistic risk planning, (3) holistic risk strategy, (4) holistic risk review and communication, (5) holistic risk implementation planning, (6) holistic risk motivation and control, (7) holistic risk systems review of results and (8) evaluation and plan modification. An illustration of how these categories fit into the proposed holistic risk management process is given in Figure 5. 
Figure 5: Proposed holistic risk management framework/cycle

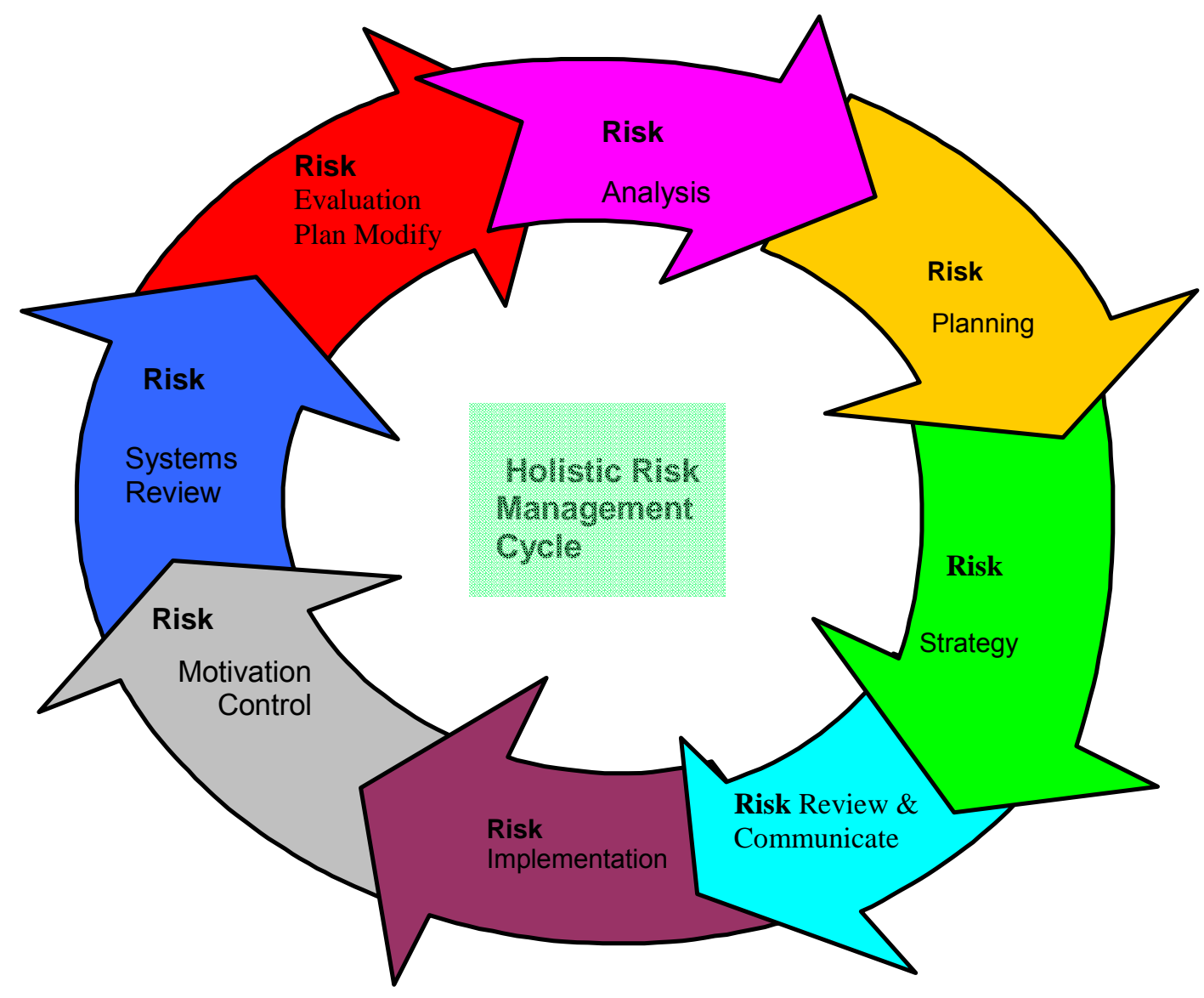

Source: Own design

In analyzing Figure 5, a framework to holistically manage risk can be established. This framework is a strategic/operational holistic risk management framework with specific reference to the South African banking industry. An explanation of the various legs of the proposed framework is given in following sections. It's fitting to call the framework the holistic risk management cycle as indicated in the middle of the framework. Each leg of the holistic risk management cycle (HRMC) represents a separate process in the management of risk in the South African banking industry.

The proposed steps in the holistic risk management process as illustrated in Figure 5 are discussed in the following sections. However, it must be emphasised that the implementation of this particular holistic risk management framework starts from any point on the holistic risk management cycle. One can start with the review of current systems, or review of results from the previous period, or planning process, or motivation and control. For the purpose of this article, let's start from the analysis of current position regarding holistic risk management.

\section{ANALYSIS OF THE CURRENT POSITION REGARDING HOLISTIC RISK MANAGEMENT}

When Bernstein (1998:111); Kloman (2000:81); Aldred (2001:142); Shimpi (2002:92); Lam (2003:121); Morrison (2004:85) and Regester and Larkin (2005:216) speak of analysis of the current position, they mean everything outside and inside a bank that is capable of affecting the survival or success of the bank. Everything from global macro-trends to new stakeholder 
developments can be included in the external and internal environment. Our competitors are part of our industry which itself is part of the external environment. The analysis of current position should include the competitor, the industry, the external environment, the internal environment, the people and the various processes within a bank.

Aldred (2001:201); Shimpi (2002:66); Lam (2003:81); Morrison (2004:39); and Regester and Larkin (2005:215), agree that the first step in the analysis of the current position regarding holistic risk management will be to establish how the bank defines risk. Risk may be defined broadly as the art of managing the uncertainties of business. The way the bank defines risk will influence the whole holistic risk management process, as each definition of risk emphasises different aspects, which requires different planning, implementation and control. After risk is defined, management should analyse opportunities available as well as possible threats. Market and consumer research should be used to do this. Management should be aware of the holistic risk management abilities of their major competitors as this may indicate further possible opportunities and threats. An analysis of past risk failures can sometimes indicate opportunities and threats. However, management should be aware of the strengths and weaknesses of the bank in order to effectively pursue the opportunities available and successfully overcome the threats.

It is also important that management should know whether there are reasonably good processes in the bank to foster holistic risk management effectively. After the strengths and weaknesses, opportunities and threats analysis, management will be in a position to establish specific holistic risk management objectives. Regardless of the form the analysis might take, the identification of trends and elements is important for a bank as it can prepare itself for what might be threats or opportunities. Shimpi (2002:183) goes a step further by proposing that a PEST model should be used to analyse the current position of the bank.

PEST is a model used to scan trends and developments in four areas:

- Political / legal trends such as those found in legislations, treaties, political stability, or the lack of it.

- Economic trends such as those found in economic development, levels of interests and other related trends.

- Socio-cultural trends such as those found in demography, differences in income, ethical groups, changes in life-style, levels of training and other related trends.

- Technological trends. National and supranational investment, technological change, technological maturity and other related trends.

Different models can be used to act on trends once they have been identified. Trends are commonly evaluated by means of a risk map, in which a trend's probability is plotted against the magnitude of the effect that it is likely to have on the bank.

Regester and Larkin (2005:204) propose that a gap analysis is ideal for analysing the current position of the bank. Gap analysis is a name generally given to identifying, specifying and taking action on the gap between a situation as it exists and the situation as we would like it to be. In risk management, a gap might be the one between satisfaction as it stands and the bank's goal for satisfaction; or there may be a gap between a bank's competencies now and the competencies it needs to unfurl certain strategies. A process for carrying out a gap analysis is described in the following six steps:

- Define the area for analysis (for example internal efficiency, competence, or losses.

- Describe the existing situation. Supplement this with metrics if necessary.

- Describe the desired situation. Set up measurable goals if this can be done. 
- Specify how the desired situation differs from the present one.

- Decide on measures to close the gap.

- Follow up and where necessary carry out corrective action.

A common approach in gap analysis is to set up a gap matrix. The next section looks at the planning leg of holistic risk management cycle.

\section{PLANNING OF HOLISTIC RISK MANAGEMENT}

Without planning, banks are subject to the winds of environmental change, yet have little means to take advantages of the prevailing currents in determining their own direction. Planning is a management function that involves setting goals and deciding how best to achieve them. Planning provides a basis for the other major functions of holistic risk management, namely: organizing; leading; and controlling (Aldred, 2001:17-24).

Strategic plans, according to Lam (2003:81), are detailed action steps mapped out to reach strategic goals. These plans address such issues as how to respond to changing conditions, how to allocate resources, and what actions should be taken to create a unified and powerful organization-wide effect ultimately aimed at strategic goals. Strategic plans are generally developed by top management in consultation with the board and with middle management. They typically cover a relatively long time horizon, often extending 3 to 5 years or more into the future. However, holistic risk management strategy must be reviewed annually. Comprehensive statements of strategic holistic risk management plans in banks often include the mission and goals because these form the basis for strategic action plans.

Tactical plans are the means charted to support implementation of the strategic plans and achievement of tactical goals. These plans tend to focus on intermediate time frames, usually 1 to 3 years. Generally, tactical plans are more specific and concrete than strategic plans. Tactical plans outline the major steps that particular holistic risk management departments will take to reach their tactical goals. In developing tactical plans, risk managers may consider a number of possibilities before settling on a final plan (the plan is, of course, subject to change, should things not progress as expected). Tactical plans are important to the success of strategic plans. Operational plans are the means devised to support implementation of tactical plans and achievement of operational goals. These plans generally consider time frames of less than 1 year, such as a few months, weeks, or even days. Unless operational goals are achieved in the bank, tactical and strategic plans will not be successful and goals at those levels will not be achieved (Shimpi, 2002:28). The next section deals with the strategic leg of the holistic risk management cycle.

\section{FORMULATION OF HOLISTIC RISK MANAGEMENT STRATEGIES}

Before any holistic risk management strategy can be formulated, it is important to establish the importance of holistic risk management in the overall objective of the bank. Management should first establish how strongly holistic risk management features in the bank's mission. A strong emphasis on holistic risk management in the bank's mission would indicate the importance of well-developed risk strategies in order to achieve the bank's overall objective.

This section reviews in more detail the different explanations of how strategies develop. However, it is important to stress that it is most unlikely that any one of the explanations will account entirely for the processes at work in the banking industry, strategy formulation needs to be understood in terms of a mix of processes (Lam, 2003:63).

Regester and Larkin (2005:255) warn that strategic choices available to the banking industry are severely limited. The environment has such a dominant influence that most banks, except the very large ones, are unable to influence their operating environments: they merely buffer from, or 
respond to, changes in that environment. Such strategy development as exists occurs through a process similar to natural selection. Variations occur within the banking processes, structures, and systems, which may or may not be deliberate. These variations are more or less relevant to the environmental pressures the bank faces, and therefore result in one bank performing better or worse than another. Those banks that perform better than others may then be able to retain, duplicate or reproduce such positive variations, and so improve their standing in relation to other banks.

Strategic planning is perhaps the most traditional view of how strategic decisions are made in the banking industry. The view here is that the elements of planning do represent a useful approach to thinking about the issues of holistic risk management strategy. However, while there is some evidence that the formalised pursuit of such a systematised approach results in some banks performing better than others, such evidence must be tentative because it is difficult to isolate planning as a dominant or determining factor in performance. It is probably more useful to conceive of the elements within the planning approach as a useful means of analysis and thinking about complex strategic problems; their formalisation into some sort of planning sequence does not, in itself, guarantee more effective holistic risk management strategies (Kloman, 2003:162). The next section looks at the review and communication leg of the holistic risk management cycle.

\section{REVIEW AND COMMUNICATION OF HOLISTIC RISK MANAGEMENT STRATEGIES}

Bernstein (1998:73); Kloman (2000:19); Aldred (2001:68); Shimpi (2002:53); Lam (2003:119); Morrison (2004:69) and Regester and Larkin (2005:197) lament that it is of little use if holistic risk management is implemented without reviewing whether it was successful or not. Management should evaluate holistic risk management activities, especially those that are successful. Such an evaluation can provide valuable information for future holistic risk management activities. There are various methods to measure holistic risk management. One way is to establish the increase in turnover generated by the effective holistic risk management. Controlling holistic risk management activities can take place before it is actually implemented to prevent possible problems. This is however very difficult due to the uncertainty involved in creating "newness". Controlling during and after implementation will thus be more valuable. Communication is the exchange of messages between people for the purpose of achieving common meanings. Unless meanings are shared, managers find it extremely difficult to influence others. For holistic risk management to be effective, it must be communicated to the majority of people working in the bank. A holistic risk management strategy not communicated is as good as no strategy at all. Risk managers spend most of their time communicating in one form or another. Studies show that they tend to prefer oral over written communication, largely because oral communication is usually more informal and timely.

A bank should actively work out systems for tracking holistic risk management performance on specific projects. It should also be able to understand progress or delays in holistic risk management in a systematic, effective and objective manner. The Federal Reserve Bank (2002:283), the Bank of England (2000:176), Kloman (2003:15), Lam (2003:142), Shimpi (2002:28), Zikmund (2005:91) and Regester and Larkin (2005:350) all agree that the review and communication of holistic risk management is crucial to the banking industry regardless of the size of the bank. The implementation of holistic risk management will be discussed in the next section.

\section{IMPLEMENTATION OF HOLISTIC RISK MANAGEMENT STRATEGIES}

Holistic risk management strategic analysis and choices are of little value to the bank unless the strategies are capable of being implemented. Holistic risk management strategic change does not take place simply because it is considered to be desirable: it takes place if it can be made to work. Bernstein (1998:210), the Federal Reserve Bank (2002:283), the Bank of England 
(2000:176), Kloman (2003:15), Lam (2003:142), Shimpi (2002:28), Zikmund (2005:91) and Regester and Larkin (2005:350) all propose that the implementation of holistic risk management in the banking industry should take the following steps:

- Goals: Sensitivity to changes in key personnel, top management perception, and impact of the strategy.

- Roles: Team building abilities, networking skills across the bank, and tolerance of ambiguity.

- Communication: Communication skills to transmit effectively to colleagues and subordinates, interpersonal skills across the bank, personal enthusiasm, and commitment.

- Negotiation: Selling plans and ideas to others and challenging the vision of the future.

- Managing up: Political awareness, in identifying potential coalitions and balancing conflicting goals and perceptions, influencing skills, helicopter perspective, to stand back from the immediate project and take a broader view of priorities.

This step is important in the management of holistic risk. If the holistic risk management is not implemented, all the efforts of creating the risk management unit will be worthless. Some banks might be weaker in the implementation of holistic risk management, which in effect will hamper future development.

Lam (2003:195) concurs with Bernstein (1998:210) and further proposes that, in order to ensure that implementation of holistic risk management ideas is successful, management can take certain measures. Firstly, there should be clear holistic risk management guidelines, specific objectives and a sharp focus on all holistic risk activities. Secondly, management can use incentives to motivate employees to be more innovative in their approach to holistic risk management. Thirdly, adequate training should be provided in the management of holistic risk management activities. Fourthly, senior management in the bank should devote sufficient time to the management of risk. Neglecting this activity will lead to unsuccessful holistic risk management. Lastly, it will be important to keep management's interest and commitment to specific holistic risk management projects.

During implementation of holistic risk management ideas, market and consumer research is again important. As market and consumer research has possibly indicated opportunities during the analysis stage, it should indicate whether these opportunities could be realised during the implementation stage. The next leg in the holistic risk management cycle is motivation and control.

\section{MOTIVATION AND CONTROL OF HOLISTIC RISK MANAGEMENT STRATEGIES}

The Bank of England (2000:176), Kloman (2003:15), Lam (2003:142), Shimpi (2002:28), Zikmund (2005:91) and Regester and Larkin (2005:350) all define motivation as what makes an individual act and behave in a certain way. It is a combination of intellectual, physiological and psychological processes that determine, in a given situation, how vigorously we act and in what direction our energy is channelled. Among the most important motivators, according to Shimpi (2002:94) and Regester and Larkin (2005:146), are:

- Status

- Personal growth and advancement

- Recognition

- Responsibility

- Challenges and stimulation at work

- Personal development and self-actualisation 
A key ingredient in the risk management system is the control factor. Often managers have too narrow a view of what constitutes management control in the strategic context. It is useful to think of control systems in two broad categories: systems of information; and measurement: This category would include financial systems such as budgets and variance analysis. However, other organisational objectives may need to be measured and controlled in different ways. Banks are attempting to develop a wider range of performance indicators which relate to the purposes identified in their strategic plan. Some of these matters lend themselves to quantified measurement, such as cost targets or staff turnover. Others have to be dealt with more subjectively, such as some aspects of quality, ethical standards or competitive standing. It is important to recognise that measurement of strategic performance will almost certainly require a mixture of measures, only some of which will be genuinely quantifiable. Systems, which regulate the behaviour of people rather than simply measuring the end result of their efforts. Rewards systems are the most important example of this type of system Aldred (2001:72). The next section deals with the systems review leg of the holistic risk management cycle.

\section{SYSTEMS REVIEW OF HOLISTIC RISK MANAGEMENT CURRENT SYSTEMS}

Holistic risk architecture provides the business framework for the risk specific functions of the bank, while the data architecture serves as the interface between the risk systems and the risk functions of the bank, and the technical architecture provides a platform for the environment on which the risk systems could operate (Lam, 2003:155 and Shimpi, 2002:191).

\section{Application Architecture}

From a holistic risk management perspective, Aldred (2001:163) suggests that holistic risk architecture should at the very least include the following components: identification of functions that is a comprehensive list of current and future risk management functions incorporated into the application architecture; location of functions that is a depicted list of the type and level of the central risk processing required by the bank; frequency of information delivered that is including scheduled and impromptu type risk reports; data storage that is a specification of the structure, including the location and detail; data integrity and ownership that is ensuring the completeness and accuracy of all risk information; interoperability that is ensured compatibility between the bank's IT strategy and the defined risk system; backup, recovery and contingency planning, ensuring business continuation (with agreed acceptable levels of disruption) should the bank encounter service outages; and system and model security, to ensure the bank's data integrity and confidentiality. The manner in which data architecture is incorporated in the holistic risk management context essentially comprises of the data storage requirements and the data integrity and ownership. The technical architecture fundamentally encompasses the design and construction of the desired risk systems the bank should incorporate, but should acknowledge existing IT systems as well as the bank's known IT strategy. Data storage, in a holistic risk management context, deals with the frequency and layout of the risk information required. As a result, the most efficient storage method should be adopted, allowing the required access with the least amount of redundancy of data (Shimpi, 2002:94).

\section{EVALUATION AND PLAN MODIFICATION}

There are a variety of financial tests that can be applied to evaluate holistic risk management projects. Evaluation according to the Federal Reserve Bank (2002:183), the Bank of England (2000:76), Kloman (2000:315), Lam (2003:242), Shimpi (2002:128), Zikmund (2005:111) and Regester and Larkin (2005:220) can use measures such as return on income, risk adjusted return on risk capital, economic value adding, and value at risk, or discounted cash flow techniques to establish if the bank is adding or destroying value. It is however important that there is a system to evaluate holistic risk management. If a risk management project is unsuccessful, the persons 
responsible for it should not be penalised for the results. It they are penalised, this might dampen future innovative activities.

After this last step in the management of holistic risk management cycle, all the information obtained during the process will be used and the whole process will start again. The framework must be reviewed at least once every year in order to take into account the ever changing environment and other technological issues.

\section{CONCLUSION}

Holistic risk management is not just buzz word in the financial services industry, nor is it a flavour of the month. It is real and institutions must manage their risk or risk the danger of disappearing from the industrial landscape. The purpose of this article is to deliberate on the work of various authors regarding the holistic risk management concept and come up with holistic risk management framework that takes into account all the facets of risk management from the holistic point of view. The requirements for the holistic risk management and the facets thereto have been proposed in order to manage risk proactively.

\section{REFERENCES}

Aldred B. 2001. Corporate Risk. London: Macmillan.

Baliman A. 1999. Auditors: Keeping the public in the dark. London: APC.

Bank of England. 2000. Internal Documents. London: Bank of England.

Banks Act. 1990. Deposit Taking Act. Cape Town: Juta.

Barton E. 2002. One World, Ready or Not. $2^{\text {nd }}$ Ed. New York: Simon and Schuster.

Bernstein P. 1998. Against The Gods. London: Oxford Press.

Chibayambuya J. 2005. The Rise and Fall of Saambou Bank. $2^{\text {nd }}$ Ed. Pretoria: MP Publishing.

Federal Reserve Bank. 2002. Internal Documents. New York: Federal Press.

Global Association of Risk Professionals (GARP). 2003. Global Risks. New York: Information Group [Online] Available from: http://www.garp.com [Accessed: 20/03/2003].

Kloman F. 2000. The art of Managing risk [Online] Available from: www.riskreports.com [Accessed: 29/11/2000].

Kloman F. 2003. Risk Plus [Online] Available from:www.riskreports.com [Accessed: 17/10/2003].

Kreps T. 1994. Change Management. New York: Berkley.

Lam J. 2003. Managing Banks. $2^{\text {nd }}$ Ed. New Jersey: Prentice Hall.

Morrison M. 2004. International Risk Management [Online] Available from: http://www.grmn.com [Accessed: 09/08/2003].

Payne B. 2000. Moves to Include Labour on Corporate Boards. Business Day, May 2.

Pinchot T. 2000. Financial Openness and National Autonomy. $3^{\text {rd }}$ Ed. Oxford: Clarendon Press. 
Price D. 2000. The Impossibility of Eliminating the Expectations Gap: Some Theory and Evidence. Critical Perspectives on Accounting, 9(3):299-330.

Regester M \& Larkin J. 2005. Risk Issues and Crisis Management. London: Kogan Page.

Roux PA. 1996. A risk-based strategic business model for a bank. Johannesburg: Rand Afrikaans University. Unpublished doctoral thesis.

Shimpi P. 2002. Integrating Corporate Risk Management. $1^{\text {st }}$ Ed. London: Heinemann.

Van Dam P. 2001. Securitisation. London: Penguin.

Vaughan G \& Vaughan O. 2004. The Aura of Accounting in the Context of a Crisis: Germany and the First World War. Accounting, Organizations and Society, 16(13):487-520.

Van Zyl C, Botha Z \& Skerritt P. 2006. Understanding the South African Financial Markets. $2^{\text {nd }}$ Ed. Pretoria: Van Schaik.

Zikmund P. 2005. Paper delivered at Conference. Risk belongs to the brave. Holistic Risk Management. Canada: Toronto 16 October 2005. 